\section{EMBRYRIDDLE}

Aeronautical University

SCHOLARLY COMMONS
Journal of Aviation/Aerospace

Education \& Research

Volume 15

Number 3 JAAER Spring 2006

Article 9

Spring 2006

\title{
Perceptions of an Aviation Flight Practicum: A Follow-Up Study of Graduates of an Aviation Flight Practicum Course
}

Lorelei E. Ruiz

John K. Voges

Keith Mortag

Follow this and additional works at: https://commons.erau.edu/jaaer

\section{Scholarly Commons Citation}

Ruiz, L. E., Voges, J. K., \& Mortag, K. (2006). Perceptions of an Aviation Flight Practicum: A Follow-Up Study of Graduates of an Aviation Flight Practicum Course. Journal of Aviation/Aerospace Education \& Research, 15(3). https://doi.org/10.15394/jaaer.2006.1495

This Article is brought to you for free and open access by the Journals at Scholarly Commons. It has been accepted for inclusion in Journal of Aviation/Aerospace Education \& Research by an authorized administrator of Scholarly Commons. For more information, please contact commons@erau.edu. 


\title{
PERCEPTIONS OF AN AVIATION FLIGHT PRACTICUM: A FOLLOW-UP STUDY OF GRADUATES OF AN AVITTION FLIGHT PRACTICUM COURSE
}

\author{
Lorelei E. Ruiz, John K. Voges, and Keith Mortag
}

\begin{abstract}
The purpose of this paper is to present the results of a follow-up survey of graduates of a collegiate aviation flight training program who completed an advanced flight practicum course prior to graduating. The AF 304-Practicum in Air Carrier Operations course at Southern Illinois University Carbondale is designed to provide advanced training and additional multi-engine flight time for flight students while providing transportation services for university personnel. Graduates of the course were asked to complete a survey regarding their experiences in AF 304. Specifically, they were asked their current employment situation, what effect(s) AF 304 had on their piloting skills and career, and what benefits they gained as a result of taking the course. Of 77 respondents, 65 indicated that they were employed as pilots at the time. Overall, the respondents agree that the course improved their flying and aeronautical decision making skills, and several noted an increase in their confidence. Additionally, they indicate having derived a variety of other benefits from the course, including more experience in various weather conditions, passenger carrying experience, a greater awareness of operations in the Air Traffic Control system, and better knowledge of advanced systems and avionics.
\end{abstract}

\section{INTRODUCTION}

Pilots hoping to gain flight officer employment with companies engaging in flight operations must first earn a Commercial Pilot Certificate and, depending on the nature of the operation, Instrument and Multi-engine airplane ratings. Graduates of collegiate flight training programs usually graduate with these certificates and ratings with a minimum of flight time. For example, Federal Aviation Regulation (FAR) Part 141 (Pilot Schools, 2004) requires a minimum of 190 flight hours for commercial pilot certification while FAR Part 61 (Certification: Pilots, Flight Instructors, and Ground Instructors, 2004) requires a minimum of $\mathbf{2 5 0}$ flight hours for the same certification. A review of the Collegiate Aviation Guide (Williamson, 2003) shows that students at most institutions offering Commercial, Instrument, Multi-engine training typically graduate with between 200 and 300 total flight hours. Those who have earned a Flight Instructor Certificate and have the opportunity to instruct in their school's flight training program will graduate with more flight time.

However, many commercial operators typically require more flight time than the typical college graduate has logged. For example, FAR Part 135.243 stipulates that to act as pilot in command (PIC), one must have attained anywhere from 500 to 1200 flight hours depending on the type of operation conducted (Operating Requirements: Commuter and On Demand Operations and Rules Goveming Persons On Board Such Aircraft, 2004). Individual operators' hiring requirements are often higher. Specific flight time hiring requirements are as cyclic as the aviation industry itself, reflecting such factors as the size of applicant pools and the state of the economy. A recent review of several Regional Airline Association (RAA) member companies' websites showed that first officer hiring requirements typically ranged from 1000 to 1500 hours total time and from 100 to 500 hours of multi-engine airplane time (Air Wisconsin Airlines Corporation, n.d.; Mesa Air Group, Inc., 2002; Trans States Airlines, n.d.).

The gap between hours required for certification and hours required for employment must be filled in some way. While some degree programs advertise as many as 75 hours of multi-engine flight training for their students (Gateway Technical College, n.d.), others only offer the minimum required for certification. Many fledgling pilots will work as flight instructors to build enough time to move on to another position where they will eventually gain the 
amount and type of flight time and experience desired by many commercial operators. However, the greatest obstacle many of these new pilots face remains how to gain more multi-engine flight experience. According to aviation career counselor Karen Kahn, "[i]t's the Catch 22 of flying...you can't get the job without the [multi-engine] time, and you can't get the time without the job." (Kahn, 1998)

In 1997, the University Aviation Association (UAA) conducted a survey of member institutions that operate transportation aircraft. The purpose of the study was to "determine how the different institutions allocate costs for the ownership and operation of the aircraft." (University Aviation Association [UAA], 1997, p. 1) The study noted that of nine responding institutions operating transportation aircraft, "...the majority of institutions operating such aircraft recognize the instructional advantages of making such aircraft available to flight education students...... [and] have the option of qualifying their advanced students for right seat 'first officer' experience in the transportation environment." (UAA, 1997, p. 5) Examples of such programs include Northwestern Michigan College (Phillips, 2002), Purdue University (Purdue University, 1995-2002), and Southern Illinois University Carbondale (SIUC, 2002).

The AF 304-Practicum in Air Carrier Operations course at SIUC is designed to provide advanced training for flight students while providing air transportation services for university personnel. The authors were unable to find any published studies related to the use of university flight transportation aircraft for advanced flight training. The purpose of this paper, therefore, is to present the results of a follow-up survey of students who have graduated from SIUC after completing the advanced flight practicum course at SIUC.

\section{BACKGROUND}

The primary mission of SIUC Aviation Flight Air Transportation aircraft is to provide for the safe and efficient air transportation of University administration and the Board of Trustees (D. A. NewMyer, personal communication, November 2004). Since 1960, numerous aircraft have been used for this purpose. Today, SIUC Air Transportation utilizes two multi-engine Cessna aircraft, a 1982 Cessna 340A and a 1981 Cessna 421C.

In 1960 , the University acquired a fixed base operator (FBO) on the field at Southern Illinois Airport (D. A. NewMyer, personal communication, November 2004). This FBO became known as SIUC's Air Institute and Service (AIS). AIS sold fuel, rented aircraft and operated an aircraft repair station during its 31-year existence. AIS also used numerous multi-engine aircraft to provide FAR Part 135 charter service in the community and FAR Part 91 flight transportation for the University administration. Students in the flight training program were allowed to fly on the FAR Part 91 university trips to gain valuable experience and build flight time. However, in the early years, there was no formal course of training or organized program for students participating in these flights. Due to the lack of a formal selection process, students were identified on an individual basis to participate in the flights.

In 1991, AIS was dissolved, including most of the FAR Part 135 charter service (D. A. NewMyer, personal communication, November 2004). The flight training continued as an Associate of Applied Science degree program and the two multi-engine Cessna's continued to provide FAR Part 91 University flight transportation needs. At that time, a course was developed that allowed students to continue to gain 'real world' experience in the more advanced aircraft. Instead of the earlier, arbitrary arrangement for gaining the experience, this more equitable system would allow students to enroll in an actual course, gain college credit, and be assured a minimum number of flight hours in a semester. The course, AF 304-Air Carrier Operations Practicum, was created and first offered in 1992.

\section{AF 304 Course Information}

AF 304 is a two credit hour, post-associate degree course offered in the Aviation Flight program at SIUC. The course offers advanced students, who have completed both the instrument and multi-engine rating courses at SIUC, the opportunity to gain practical multi-engine flight experience. This experience involves flying University personnel in a FAR Part 91 corporate flight department format. The course listing in the University's 2003-2004 Undergraduate Catalog (Southern Illinois University Carbondale, 2002) reads as follows:

304-2 Practicum in Air Carrier Operations. Students gain practical experience and training by participating as flight officers on passenger aircraft flights. Enables students to practice, under close supervision, the role of first officer within a passenger carrier format. Course includes 20 hours of flight time and a minimum of 40 hours pre- and post-flight activities and instruction. (p. 160)

The catalog guarantees 20 hours of flight time, yet the reality is that students average around $\mathbf{4 0}$ hours of flight, most of which is PIC time. The course is pass/fail, and there is no simulator or flight training device (FTD) time in the course.

Fundamental goals of the course are to develop both the student's skill level controlling the aircraft and exercising the student's capacity for making in-flight decisions with respect to weather, passenger comfort, 
altitude selection, etc. The student gains the additional benefit of operating in a crew environment. The SIUC Air Transportation pilots serve as course instructors. Referred to as Training Captains (Southern Illinois University Carbondale Aviation Flight, n.d.), the instructors deliver approximately 40 hours of ground training. This includes 20 hours of training on systems specific to the two transportation aircraft. It also provides in-depth analysis of departure, en route, and arrival considerations for trip planning utilizing available route planning options and weather services. Additional topics include familiarization with FAR Part 135 regulations and high altitude flight physiology to meet the training and endorsement requirements of FAR $61.31(\mathrm{~g})$, Additional training required for operating pressurized aircraft capable of operating at high altitudes (Certification: Pilots, Flight Instructors, and Ground Instructors, 2004). The remaining 20 hours of ground instruction covers trip specific items, including preflight and post-flight briefings.

Throughout the course, students gain experience in a variety of weather conditions, in all classes of airspace, both day and night, typically under instrument flight rules. Typical destinations include Springfield, IL (Class C) and airports in the Chicago and St. Louis metropolitan areas (Class B, D), with the occasional additional destination outside the state of Illinois. Also, emphasis is placed on the use of Jeppesen charts for navigation. Since most Aviation Flight students utilize the FAA's Terminal Procedures publications and En Route Low Altitude charts during their early training, this is typically their first exposure to the Jeppesen format, which is the format used predominantly in the industry.

\section{Aircraft Used in AF 304}

The aircraft currently utilized include a 1981 Cessna 421C and a 1982 Cessna 340A, with the Aviation Flight Program's training Cessna 310R's used on an occasional basis for back-up. The Cessna 310R, as the multi-engine trainer for the SIUC Flight Training Program, facilitates the student's transition to the Cessna 340A. From a performance perspective, the $310 \mathrm{R}$ is better equipped than most multi-engine trainers to prepare students for the higher performance characteristics of the Cessna $340 \mathrm{~A}$ and the Cessna 421C. Sharing a common manufacturer leads to quicker cabin familiarization. There are significant differences between the Cessna 310R and these two aircraft which require an understanding of more advanced aircraft systems combined with operational practices and procedures that are new to the student.

The Cessna 340A is the closest of the two aircraft to the Cessna 310R and orients the students to operating an aircraft equipped with turbocharged engines, a pressurization system, anti/de-ice capability and airborne weather radar. It also has vortex generators, which improve performance characteristics.

The Cessna 421C possesses even more advanced equipment and has unique operational characteristics which present new training opportunities to the student. Like the Cessna 340A, it is equipped with turbocharged engines, a pressurization system, anti/de-ice capability, airborne weather radar, and vortex generators. In addition, the avionics equipment in the Cessna 421C include a Garmin GNS 430 Global Positioning System (GPS) with Mode S traffic and a WX500 StormScope for lightning detection. The aircraft's RDR2000 Weather Radar detects precipitation intensity and displays this information on an Avidyne EX500 multi-function display. The Avidyne can also display satellite downlinked weather in textual format as well as Nexrad radar images and navigational information taken from the GPS. The Cessna $421 \mathrm{C}$ also utilizes spoilers for speed control.

\section{Student Enrollment in AF 304}

Due to the nature of the operation, enrollment is limited and admission to the course is selective. Factors considered in the maximum number of students allowed to enroll include changing trip schedules, forecast aircraft downtime due to scheduled and unscheduled maintenance, and each student's individual scheduling needs. Fall and Spring semesters usually average six students, with a maximum of three students in the eight-week summer session. Students applying to the course must submit an application for consideration. To be eligible for the course, this application must demonstrate the student (a) has completed SIUC's instrument rating and multi-engine rating courses with a grade of $\mathrm{C}$ or better, (b) has a written recommendation from their instructor in one of these courses or from the Chief Flight Instructor, (c) is eligible for University admission, (d) maintains a second class medical, and (e) agrees to furnish suitable professional attire while acting as a crew member and be available for flights outside of normal business hours. Applicants must be approved by the AF 304 Selection Committee, which consists of the Chief Flight Instructor and the AF 304 Training Captains. Notification of approval is informal, with the Training Captains contacting the student either by phone or in person. Once approval is granted, a letter of authorization is sent to the program's academic advisor to allow the student to enroll in the course.

Typical Flight Sequence in AF 304

Flights are normally conducted under FAR Part 91 on an instrument flight plan and follow a typical flight 
sequence. The schedule averages 35 trips per month, and each leg averages about one hour in duration. The preparation for the flight begins with the student's arrival at least one hour prior to departure in order to prepare for the flight. The first step is to obtain and analyze the weather, choose an appropriate route and altitude, then file a flight plan. The student must take into account departure, en route, and arrival considerations, balancing these against the weather and any limitations of the aircraft when making a go/no-go decision.

The student will determine fuel requirements, perform weight and balance calculations, and complete a preflight inspection of the aircraft. This inspection includes organizing the cockpit for the flight and ensuring the appropriate amenities are available in the cabin for passengers. Calculations are performed using either the conventional form from the pilot's operating handbook or a computer spreadsheet program designed to yield the same results.

As passengers arrive for their departure, the student is encouraged to greet them and interact with them as appropriate to each circumstance. Professional dress is required. This aspect of the experiential training is invaluable as the passengers often include the University's President, the Chancellor, Deans of the Medical School and various Colleges, Athletic Department Heads, members of the Board of Trustees and even state and national politicians and business leaders visiting on University business.

\section{METHODOLOGY}

Research Questions

The researchers were interested in determining answers to the following questions:

1. What positions do AF 304 graduates hold now?

2. What effect do AF 304 graduates believe the course has had on their piloting skills?

3. What impact do AF $\mathbf{3 0 4}$ graduates believe the course has had on their flying careers?

4. What benefits do AF 304 graduates believe they have realized as a result of taking the course?

\section{Survey Procedures, Population Size, and Instrument}

The authors created a survey instrument to gain feedback on the AF 304 course. The instrument was reviewed for validity by four former AF 304 students currently working as flight instructors for SIUC. The population to be studied consisted of all former students of AF 304, a total of 137 course graduates identified using course records. Addresses for 133 of the 137 course graduates were compiled from SIUC Alumni Association records and the Federal Aviation Administration's (n.d.) Interactive Airmen Inquiry web site. Addresses for four course graduates could not be obtained from either of these sources. The 4-page survey was sent to the 133 course graduates with a cover letter and a return envelope. As King, Pealer and Bernard (2001) note some studies that suggest an increased response rate when using green paper, the surveys were printed on green paper. Surveys were also coded to allow for targeted follow-up of non-respondents. This follow-up mailing, including another copy of the survey and a return envelope, was sent 4 weeks after the first to those who had not yet returned the original survey. Six surveys and/or follow-up mailings were returned as undeliverable by the US Postal Service.

The survey consisted of three parts: Demographics, General, and AF 304. The Demographics section asked the respondents to indicate graduation date, gender, current employer and position, job history, and flight time. The General section requested information regarding the respondent's own flight training, reasons for taking AF 304, and career goals. Finally, the AF 304 section requested information specific to the AF 304 course. This included a battery of 19 statements (see Appendix A) rated on a fivepoint Likert scale ( 1 = strongly disagree, 2 = disagree, $3=$ neither agree nor disagree, $4=$ agree, $5=$ strongly agree) and several short answer questions.

Statistics used to analyze data include descriptive statistics (frequency counts, means, and standard deviations). Reliability testing of the 19 Likert scale items yielded an alpha of .85 overall, indicating an acceptable level of internal consistency (UCLA Academic Technology Services, n.d.).

\section{RESULTS AND ANALYSIS}

Of 127 course graduates contacted, 77 completed responses were received, for a $61 \%$ response rate. The gender distributions of respondents included 71 male and 6 female graduates of the course. This compares to a gender distribution of 113 male and 14 female among the 127 graduates contacted. Forty-nine respondents (64\%) indicated that they had received all of their flight training up through Commercial AMEL, ASEL, Instrument through SIUC. The remaining $28(36 \%)$ indicated that they had earned the Private Pilot certificate elsewhere before completing the Commercial AMEL, ASEL, Instrument at SIUC.

Research Question 1: What positions do AF 304 graduates hold now?

Respondents were asked to indicate both their current employer and current position. Overall, respondent employment in the aviation industry is high. The airlines 
and flight schools appear to be the most common employer of course graduates. Sixty-five ( $84 \%$ ) respondents reported current employment as a pilot, eight $(10 \%)$ reported working in some other aspect of the aviation industry, and four $(5 \%)$ reported working in some field other than aviation. Of the 65 reporting employment as a pilot, 5 indicated current employment with a major airline, 30 with a regional airline, and 17 reported current employment as a flight instructor. The remaining 13 reported employment with charter operations, corporate flight departments, the military, or as pilots available for hire on contract. (See Table 1) Three respondents indicated two current flying jobs (all instructor/passenger charter). It should be noted that of the four respondents reporting a current position in an industry other than aviation, two had been recently furloughed from major airlines and one had been recently furloughed from a regional airline.

Table 1

Current Positions Reported by AF 304 Graduates

\begin{tabular}{lc}
\multicolumn{1}{c}{ Position } & N \\
\hline Pilot & 5 \\
Airlines (Major) & 0 \\
Airlines (National) & 30 \\
Airlines (Regional) & 1 \\
Charter (cargo) & 3 \\
Charter (passenger) & 2 \\
Contract & 7 \\
Corporate & 17 \\
Instructor & 2 \\
Military & 8 \\
Other, aviation & 4 \\
Other, non-aviation &
\end{tabular}

\footnotetext{
Note. Two respondents reported two current flying positions.
} 
Research Question 2: What effect do AF 304 graduates believe the course has had on their piloting skills?

Respondents were asked to indicate whether AF 304 was beneficial to their flying skills. The data show that course graduates strongly agree $(M=4.65, S D=.51)^{t}$ that the training experience has been beneficial to their flying skills. They also strongly disagree $(M=1.25, S D=.46)$ that the course has had no effect on flying skills. Regarding aeronautical decision making (ADM) skills, the respondents agree $(M=4.31, S D=.57)$ that the course has been beneficial to their ADM skills. They also disagree $(M=$ $1.49, S D=.55$ that the course has had no effect on their ADM skills. Additionally, respondents agree that the course has enhanced their confidence with respect towards flying in adverse weather $(M=4.31, S D=.75)$ and the National Airspace System $(M=4.49, S D=.50)$.

Research Question 3: What impact do AF 304 graduates believe the course has had on their flying careers?

Respondents were asked to indicate what their career goals had been when they enrolled in the AF 304 course. A total of 67 respondents indicated that their goal was to become an airline pilot, while 12 indicated that they wanted to become charter or corporate pilots. Other responses are shown in Table 2. The two respondents indicating Other noted "Pastor/Church Planter" and "a career in aviation" as career goals. Several respondents reported more than one goal. Additionally, 12 of the respondents indicated that the course changed their career goals. Narrative responses regarding the changes are included in Appendix B. Specifically, seven of the comments reflect a change favorable toward a career in corporate or charter flying, while two reflect a change in the opposite direction.

Table 2

Respondents Reporting Specific Career Goals Prior to Taking AF 304

Career goal

Airline pilot

Corporate pilot

On-demand charter pilot

Flight instructor

Military pilot

Undecided

Other
$\mathrm{N}$

12

5

3

2

1

2

Note: Nine respondents reported multiple career goals. 
Overall, respondents agree $(M=4.32, S D=.65)$ that they have used their AF 304 experiences in their flying careers. They generally agree $(M=3.51, S D=.99)$ that having AF 304 on a transcript/resume helped them obtain a job interview. They also agree that AF 304 has been important in obtaining employment as a pilot $(M=3.71, S D$ $=.93$ ).

Respondents who reported a current flying position agree $(M=4.43, S D=.49)$ that they have used their AF 304 experiences in their flying careers. They generally agree $(M$ $=3.62, S D=1.01$ ) that having AF 304 on a transcript/resume helped them obtain a job interview. They also agree that AF 304 has been important in obtaining employment as a pilot $(M=3.83, S D=.94)$.

Research Question 4: What benefits do AF 304 Air Carrier Practicum graduates believe they have realized as a result of taking the course?

Respondents strongly agree $(M=4.88, S D=.32)$ that AF 304 is a good course, and agree $(M=4.03, S D=$ .73) that it is a challenging course. They strongly disagree $(M=1.21, S D=.64)$ that the course is a waste of time. They agree $(M=4.19, S D=.69)$ that the course presented realistic scheduling considerations that better prepared them for a career as a pilot. Regarding passenger-carrying responsibilities, the respondents agree $(M=4.44, S D=.52)$ that the course gave them a better appreciation for the responsibilities associated with carrying passengers and that the pressure associated with transporting university executives is representative of the responsibilities in 'real world' charter/corporate flying $(M=4.05, S D=.76)$.

Respondents strongly disagree $(M=1.29, S D=$ .53) that there is no benefit to having completed AF 304. They were asked to list briefly any benefits they believed they received from AF 304. These narrative responses were summarized and sorted into three general categories (Pilot, Aircraft, and Environment) and further into 16 subcategories (see Table 3). Specific benefits most often reported include 'real world' experience (33), experience in instrument meteorological conditions (29), and additional multi-engine flight time (23).

Respondents strongly agree $(M=4.83, S D=.38)$ that they would recommend AF 304 to future flight students. Further, when asked to indicate whether they would highly recommend the course, respondents strongly agree $(M=$ $4.75, S D=.59$ ) that they would highly recommend AF 304 to future flight students. Additionally, respondents strongly disagree $(M=1.2, S D=.40)$ with the statement that they would not recommend AF 304 to future flight students. 
Table 3

Perceived Benefits of the AF 304 Course

Benefit

$\mathbf{N}$

Pilot

Multi-engine flight time

Improved ADM skills/situational awareness

17

Improved understanding of ATC NAS

16

Improved flying skills

12

Increased confidence

11

Introduction to crew concepts

Professionalism

Getting a job quickly after graduation

Aircraft

Knowledge of advanced systems and avionics

Experience in cabin class Cessnas

Knowledge of aircraft care

Environment

"Real world" experience/operations

Experience in IMC/various weather conditions

Passenger carrying experience

IFR flight planning

High altitude operations 


\section{CONCLUSIONS}

An Aviation Flight Practicum course is perceived to be beneficial by those students who choose to pursue the AF 304 course at SIUC. With respect to the positions presently held by graduates of the course, of the 77 respondents completing the survey, 65 currently held flying positions and an additional 3 had recently been furloughed from a flying position. Those respondents currently flying reported holding positions as airline pilots (35), flight instructors (17), corporate/charter pilots (11), and military pilots (2). This demonstrates that employment as a pilot was high at $84 \%$, with an additional $10 \%$ of respondents being employed in an aviation related field. As' to the course having an effect on their piloting skill, overall, the respondents agree that the course improved both their flying skills as well as their aeronautical decision making skills. What impact did the course have on the respondents' flying careers? Those respondents who reported a current flying career also agree that the experience gained in the course has helped them secure employment as a pilot. Of interest is the fact that 12 respondents $(16 \%)$ indicated that the course was instrumental in changing their original career goals in one way or another. In some instances the course directed students to pursue a corporate or charter flying position while others were inclined toward airline flying. Respondents additionally indicate many benefits derived from taking the course.

From the responses, it is clear that the Practicum in Air Carrier Operations achieves numerous objectives for these students. Their responses demonstrate why the course enjoys near capacity enrollment each semester. Specifically, the course provides a venue to help them build critically important multi-engine experience, while allowing them the opportunity to gain real world flight experience in the National Airspace System in weather while carrying passengers.

Overall, graduates of the AF 304 course appear to be quite successful in gaining employment as pilots, as evidenced by the fact that 68 of the 77 respondents reported current or recent employment as a pilot. In light of the current employment data gleaned from the study, one area for further study would be comparing job placement/career progression of AF 304 graduates to other aviation flight graduates to help further determine the benefit of the course to the student. Additional research opportunities could be considered by comparing similar course offerings at other flight training institutions along with the resources and criteria necessary for developing such courses.t

Lorelei E. Ruiz holds an M.S. in Education and a B.S. in Aviation Management, both from Southern Illinois University at Carbondale (SIUC). She is an Assistant Professor and Assistant Chief Flight Instructor in the Department of Aviation Management and Flight, College of Applied Sciences and Arts, at SIUC.

John K. Voges is an Assistant Professor and Assistant Chief Flight Instructor in the Department of Aviation Management and Flight at Southern Illinois University Carbondale (SIUC). Professor Voges holds an Airline Transport Pilot certificate and Certified Flight Instructor certificate with ratings for single-engine, multi-engine and instrument ratings. He has served as the Safety Officer for the Flight program since 1990 and as a Flight Transportation Pilot since 1996 with nearly 6,000 hours of flight experience. He teaches Aviation Industry Regulations (AVM 371) in the SIUC's Off Campus program. He earned a B.A. degree in Management from the University of Illinois at Springfield and a M.S. in Workforce Education and Development from SIUC.

Keith Mortag is the Senior Flight Transportation Pilot for SIU with over 13,000 flight hours. He is also part of the Faculty and has been an Assistant Chief Flight Instructor in the Aviation Flight program at SIU since 1986. In 1995, he earned a MAS degree in Workforce Education with a focus on CRM and Curriculum Development. He has enjoyed working with the AF304 Flight Practicum course since its inception. 


\section{REFERENCES}

Air Wisconsin Airlines Corporation. (n.d.). Pilots. Retrieved June 9, 2004 from http://www.airwis.com/car pilots.htm?linkSrc $=6$

Andrews University, Aeronautical Technology. (n.d.) Retrieved June 10, 2004 from http://www.andrews.edu/academic/cot/aerotech.php3

Certification: Pilots, Flight Instructors, and Ground Instructors, 14 C.F.R. $§ 61$ (2004).

Federal Aviation Administration. (n.d.). Airmen inquiry site. Retrievable from http://registry.faa.gov/amquery.asp

Gateway Technical College, Aeronautics Pilot Training. (n.d.) Retrieved June 17, 2004 from http://cws.gateway.tec.wi.us/departments/Aviation/PilotTraining.htm

Kahn, K. (1998). Questions and answers with Karen Kahn. Retrieved June 17, 2004 from http://www.studentpilot.net/pilotcareers/questions.html\#me

King, K. A., Pealer, L. N., \& Bernard, A. L. (2001). Increasing response rates to mail questionnaires: A review of inducement strategies. American Journal of Health Education, 32(1), 4-15.

Mesa Air Group, Inc. (2002). Pilot position FAQs and online application. Retrieved June 9, 2004 from http://www.mesaair.com/career opportunities.asp

Operating Requirements: Commuter and On Demand Operations and Rules Governing Persons on Board Such Aircraft, 14 C.F.R. $\S 135$ (2004).

Phillips, W. (2002, December). The college conundrum: Choosing a school that's right for you. AOPA Flight Training, $14(12), 20-26$.

Pilot Schools, 14 C.F.R. § 141 (2004).

Purdue University, Aviation Technology. (1995-2002) The history of the FLT program. Retrieved June 10, 2004 from http://www.tech.purdue.edu/at/information/fthistory/

Southern Illinois University Carbondale (2002). Aviation Flight. Southern Illinois University Carbondale 2003-2004 Undergraduate Catalog. 159-161.

Southern Illinois University Carbondale Aviation Flight (n.d.). AF 304 Operations Manual. Unpublished manuscript.

Trans States Airlines. (n.d.). Career opportunities. Retrieved June 9, 2004 from http://www.transstates.net/careers.html

UCLA Academic Technology Services. (n.d.). SPSS FAQ: What does Cronbach's alpha mean? Retrieved July 19, 2004 from http://www.ats.ucla.edu/stat/spss/fag/alpha.html

University Aviation Association. (March 4, 1997). College and university air transportation survey report. (Available from the University Aviation Association, 3410 Skyway Drive, Auburn, AL 36830)

Williamson, C. (Ed.). (2003). Collegiate aviation guide. Auburn, AL: University Aviation Association. 


\section{Footnotes}

'For the purposes of this paper, when discussing results of Likert scale items, a mean of less than 1.5 indicates strong disagreement with the statement, 1.5 to 2.5 indicates disagreement, between 2.5 and 3.5 indicates neither agree nor disagree, 3.5 to 4.5 indicates agreement, and greater than 4.5 indicates strong agreement. 


\section{Aviation Flight Practicum}

\section{Appendix A}

Applicable Likert statements from AF 304 graduate follow-up survey

1. AF 304 is a good course.

2. AF 304 is a waste of time.

3. AF 304 is a challenging course.

4. AF 304 presented realistic scheduling considerations that better prepared me for a career as a pilot.

5. AF 304 gave me a better appreciation for the responsibilities associated with carrying passengers.

6. My AF 304 training experience has been beneficial to my flying skills.

7. My AF 304 training experience had no effect on my flying skills.

8. My AF 304 training experience has been beneficial to my aeronautical decision making skills.

9. My AF 304 training experience had no effect on my aeronautical decision making skills.

10. I believe having AF 304 on a transcript/resume has helped me obtain a job interview.

11. My AF 304 training experience has been important in my obtaining employment as a pilot.

12. The pressure associated with transporting university executives is representative of the responsibilities in 'real world' charter/corporate flying.

13. AF 304 enhanced my confidence with respect towards flying in adverse weather.

14. AF 304 enhanced my confidence with respect towards flying in the National Airspace System.

15. I have used my AF 304 experiences in my flying career.

16. I see no benefit to having completed AF 304 . 
17. I would recommend AF 304 to future flight students.

18. I would highly recommend AF 304 to future flight students.

19. I would not recommend AF 304 to future flight students. 


\section{Appendix B}

Narrative answers regarding effect of AF 304 on career goals

1. Although I enjoyed the experience greatly and increased my multi \& actual time, I realized that I did not want to fly as a charter pilot. Before AF 304 I had considered both airline and charter careers. Taking the course allowed me to realize I only wanted to be an airline pilot.

2. This is rather hard to answer/comment. I mainly took AF 304 because I was dedicated to one day getting an airline job. The experience received from AF 304 was invaluable to obtaining my airline goal. AF 304 provided me preparation in regard to "real world" flying \& transporting "real world" passengers.

3. Made me realize I didn't want to be a charter pilot but experience was priceless

4. It opened my eyes to corporate aviation.

5. Narrowed focus into becoming corporate pilot.

6. It helped me discover the benefits of corporate aviation. Weighing both sides, I don't think I could ever want to fly airline. W/ my current job, I work less \& get paid more!

7. It introduced me to the world or realm of flight that I have been in for the past 3 years. I wanted to be able to market myself in a charter or corporate pilot interview. This gave me more areas of opportunity for work after graduation.

8. AF 304 showed me air transportation on a more personal level. I enjoyed interacting with the user \& get to do just that in the military now.

9. It gave me better insight of corporate aviation. I am willing to pursue charter flying in lieu of the airlines

10. I am now more open to corporate flying. AF 304 has broaden [sic] my perspective to other types of flying positions.

11. The program got me badly needed twin time at a reasonable cost. I think all students should be able to get at least $100 \mathrm{hrs}$ of multi time in school if they are motivated enough. Through a school sponsored program such as AF 304 or a school sponsored club. Multi time is the most important time your students are getting towards career advancement.

12. further solidified my passion and interest in corporate aviation. Also gained an interest of a future entrepreneurship in corporate/charter travel 